\title{
Assessment of the socio-economic development of the region (on the example of the Chuvash Republic)
}

\author{
Polina Gorbunova ${ }^{1, *}$, Gennady Denisov ${ }^{1}$, Elena Perfilova ${ }^{1}$ and Anna Zakharova ${ }^{2}$ \\ ${ }^{1}$ Department of Sectoral Economics, Chuvash State University, Cheboksary, Russia \\ ${ }^{2}$ Department of Social and Clinical Psychology, Chuvash State University, Cheboksary, Russia
}

\begin{abstract}
The article proposes a methodology for an indicative assessment of the socio-economic development of the region in order to ensure the sustainability of development. The author's methodology is based on the principles of indicative management; based on the use of a system of indicators of development indicators, intervals of threshold values; is a stepby-step process of assessing the social and economic development of the region; takes into account the contribution of each factor to ensuring sustainable development; allows you to identify "strong" and "problem" areas of social and economic development of the region. The analysis of the results obtained in dynamics makes it possible to assess the effectiveness of development indicators.
\end{abstract}

A new look at the role of the forecasted Russian economic science has affirmed along with the awareness of the potential opportunities of modern entrepreneurial regulation of tools and mechanisms of activity. Being an indispensable element of the decision-making process and being in a close relationship with planning for a long time, it has now been predicted to be dominant component of this process.

The logical consequence of the strengthening of the role of forecasting in solving the problems of modern management was to increase the requirements for the validity and reliability of forecast estimates. However, the level of compliance of the modern prognostic apparatus with these new requirements remains excessively low. Even the use of adaptive models, with the help of which it is possible, as a rule, to achieve the necessary level of adequacy in the description of the predicted of the processes, only partially solves the problem of improving reliability [9].

The modern economy generates processes with such complex dynamics that the identification of its regularities by the apparatus of modern forecasting is often an unsolvable task. The improvement of this apparatus, first of all, needs new ideas and new approaches, on the basics of which it is possible to implement mechanisms and ways of reflecting the dynamics formed under the influence of effects, the possibility of which in the future is not found in the data of the data historical period [1].

At the same time, future trends grow out of the past. This fact cannot be ignored and, therefore, it must also be reflected in the forecast trajectory. There is a clear contradiction,

*Corresponding author: polina7103@mail.ru 
overcoming which will contribute to the formation of a new view of the formation of a new view of forecasting as a pre-emptive reflection in the probabilistic environment of the representation of the process under study in the form of a trajectory built on the basics of objective trends and subjective expectations. As a result, there is an opportunity to make informed decisions, as any management decision, in the end, is a kind of reaction to the forecast view of the future of the managed object, thanks to forecasts, managers are able to assess undesirable trends and threats in a timely manner.

Assessment of opportunities to achieve the goals requires a comprehensive account of the dynamics of the main indicators of the economy of the region, reflecting its potential for reproduction, development and impact on the social sphere. In the regard, statistical data for the period from 2016 to 2018 were used (table 1) [2,3,8].

Table 1. Main indicators of social and economic development of the Chuvash Republic for 20162018 (million rubles).

\begin{tabular}{|c|l|c|c|c|}
\hline \multirow{2}{*}{ Indicators } & \multicolumn{3}{c|}{ Million rubles in the corresponding } \\
\cline { 3 - 5 } & & $\mathbf{2 0 1 6}$ & $\mathbf{2 0 1 7}$ & $\mathbf{2 0 1 8}$ \\
\cline { 3 - 5 } & & 181485,90 & 215387,40 & 237295,80 \\
\hline 1 & Total region product & 371787,9 & 423508,10 & 466585,70 \\
\hline 2 & $\begin{array}{l}\text { Production of goods and services by } \\
\text { major industries }\end{array}$ & 35269,70 & 38514,50 & 41663,83 \\
\hline 3 & $\begin{array}{l}\text { Volume of investments (in fixed assets) } \\
\text { from all sources of financing }\end{array}$ & 98876,17 & 109183,94 & 111033,88 \\
\hline 4 & Area income & 180725,70 & 201291,80 & 228481,20 \\
\hline 5 & Income of people & 176097,60 & 199045,50 & 225681,20 \\
\hline 6 & Expenses and savings of the population & & & \\
\hline
\end{tabular}

The developed schemes of multidimensional predictive calculations are quite applicable for solving real problems of sufficiently large size. The class of such tasks should include, first of all, the development of forecasts of socio-economic development of regions [4]. The number of different indicators whose expected values need to be calculated in solving this problem is so large that an attempt to build a single model that reflects the interaction between all these indicators is unlikely to be successful. In such a situation, it is possible to group indicators on any sign (sector of economy, branch, a source of the income, etc.) that allows to reduce considerably dimension of the solved problem and by means of its reduction to sequence of problem of the smaller sizes.

The model of multidimensional combined forecasting involves the use of a deterministic matrix predictor. This predictor makes sense to building those situations when the possibility of using statistical modeling methods is completely excluded. An example is a situation in which the researcher has only two, three observations [5].

The model is constructed under the condition that the growth of any of the indicators is formed under the influence of all the others, being as it were the total value. Moreover, each indicator individually has a minor impact, and among them there are no predominant ones.

The main advantage of this approach is that it can be used to perform calculations for multivariate series of dynamics even when the researcher has observations for only two periods. However, the statistical reliability of such predictive calculations is not checked and is based mainly on the assumption that even if the nature of the dynamics of the predicted processes changes, the structure of the predictor itself, as a rule, will change slightly. As the practice of predictive calculations shows, the use of this model is preferable to conventional calculations using growth rates, which do not take into account the interaction between the simulated indicators [6]. 
Conventional statistical modeling methods do not allow for a short time series of observed values (three numbers) to give an acceptable forecast estimate. In this regard, there is a predictor in the calculation scheme, which is a means of eliminating these problems and allows predictive estimates not for individual indicators, but simultaneously for a set of all indicators of the same level in relation to each other. The results of the calculations are presented in table. 2 .

Table 2. Forecast estimates of the main indicators of social and economic development of the Chisvash Republic for 2020 (million rubles)

\begin{tabular}{|c|l|c|c|c|c|}
\hline & \multicolumn{1}{|c|}{ Indicators } & \multirow{2}{*}{$\begin{array}{c}\text { A formalized } \\
\text { forecast }\end{array}$} & $\begin{array}{c}\text { Intuitive } \\
\text { forecast }\end{array}$ & \multicolumn{2}{c|}{$\begin{array}{c}\text { A combined } \\
\text { forecast }\end{array}$} \\
\cline { 5 - 6 } & & 291217,2 & 273827,9 & 268950,4 & 267133,0 \\
\hline 1 & Total region product & 588303,8 & 547327,2 & 515692,8 & 520236,7 \\
\hline 2 & $\begin{array}{l}\text { Production of goods } \\
\text { and services by major } \\
\text { industries }\end{array}$ & 57599,7 & 54249,2 & 45685,6 & 48549,0 \\
\hline 3 & $\begin{array}{l}\text { Volume of investments } \\
\text { in fixed assets) from } \\
\text { all sources of financing }\end{array}$ & 143687,5 & 130362,9 & 124687,4 & 128357,2 \\
\hline 4 & Area income & 282050,2 & 263650,1 & 243424,8 & 252824,7 \\
\hline 5 & Income of people & 281750,3 & 260824,5 & 236624,8 & 254150,9 \\
\hline 6 & $\begin{array}{l}\text { Expenses and savings } \\
\text { of the population }\end{array}$ & & & & \\
\hline
\end{tabular}

Combined trajectories I and II, as well as the expert trajectory differs significantly from the calculated trajectory: the growth rate of the latter is much higher. Obviously, this is due to the fact that experts in their expectations focused on a decrease in the growth rate of inflation, while the estimated forecasts reflected the inflation rates of recent periods. This difference is the essence of multi-level combined forecasting, which allows to take into account those trends that have not yet had time to manifest themselves in economic reality.

So, after analyzing these indicators, we can conclude that the developed forecasting apparatus can really be used in the practice of mass calculations that take place in the formation of variants of socio-economic development of the region. Moreover, the use of this device introduces elements of a systematic approach to forecast calculations, which organizes the whole multi-stage process and significantly increases the efficiency of solving regional forecasting problems [7].

As is known, theoretical and applied aspects of modeling qualitative variables have been intensively developed only in the last decade. The apparatus of such modeling was the basis for the implementation of the idea of forecasting expert preferences.

Of particular interest are models based on the idea of combining adaptive principles and expert expectations. The constructed computational schemes of the developed models are an effective tool for complex predictive calculations. Their verification at the regional level confirmed the versatility, flexibility and reliability of this tool.

\section{References}

1. A. Emelyanov, E. Vlasova, R. Duma. Simulation of economic processes: studies. Manual. Moscow: Finance and statistics, 2004, 368 p.

2. Finances of The Chuvash Republic. 2018. Cheboksary, 2018. 
3. Industry Of The Chuvash Republic. Cheboksary, 2018, $120 \mathrm{p}$.

4. P. Gorbunova, E. Perfilova, A. Babaeva. Methodical problems of classification of regions on the level of social and economic development. Far East Con (ISCFEC 2018). Proceedings of the International Scientific Conference. Cep. "Advances in Economics, Business and Management Research" Far Eastern Federal University. 2019, p. 10981100.

5. S.M. Kadochnikov "Foreign direct investment in transition economies", Ekonomika regiona, 2005, №4, pp. 140-170

6. Smirnov V., Semenov V., Kadyshev E., Zakharova A., Perfilova E. Management of development efficiency of the russian economy. Proceedings of the International Scientific Conference «Social and Cultural Transformations in the Context of Modern Globalism» (SCTCMG 2018). The European Proceedings of Social \& Behavioural Sciences EpSBS. 2019. Volume LVIII. pp. 1872-1877.

7. Smirnov V.V., Zakharova A.N., Talanova T.V., N.G. Gubanova, V.L. Semenov, N. V. Semenova, Shikanova A.N. Analysis of Interaction of Russian Entrepreneurship Factors. Proceedings of the 34th International Business Information Management Association Conference (IBIMA). Vision 2025: Education Excellence and Management of Innovations through Sustainable Economic Competitive Advantage. 2019.

8. Statistical Yearbook of the Chuvash Republic, 2018. Cheboksary, 2018. - 474 p.

9. V. Davies, V. Tinyakova. Predictive models of expert preferences: monograph. Voronezh: Publishing house Voronezh, 2005, 248 p. 